\title{
Improvement of the integrated management system of energy companies by the implementation of electronic educational resources
}

\author{
M. Berezyuk ${ }^{1}$, A. Rumyantseva ${ }^{1} \&$ G. Chebotareva ${ }^{2}$ \\ ${ }^{1}$ Department of Environmental Economics, \\ Ural Federal University, Russia \\ ${ }^{2}$ Academic Department of Banking and Investment Management, \\ Ural Federal University, Russia
}

\begin{abstract}
The certification in an environmental management system is one of the most important factors of the competitiveness of international energy companies. The industry leaders are certified by an integrated management system (IMS). The company personnel competence level in industrial safety, product quality, labor protection, and environmental management is a necessary condition for environmental safety improvement. The authors have developed an electronic educational resource - a website to be accessed by all employees of the company. The resource includes methodical and informational material on the functioning of the IMS of the enterprise. The economic effect from the resource usage is the reduction of the cost and training time and the increase of the competence level of the company's personnel.

Keywords: integrated management system, environmental management, educational electronic resource, personnel training.
\end{abstract}

\section{Introduction}

The work of large energy companies is characterized by an orientation towards the international market and involves compliance with the respective international environmental standards. Furthermore, the energy industry in the Russian 
Federation is among the top three industries in terms of the size of the negative impact on the environment [1].

Increasingly, more companies are considering the implementation of an integrated management system (IMS). This decision is associated with an organization's desire to compete head to head with Russian and Western companies, which have already verified their accomplishments by obtaining certification in the areas of quality management, environmental management and occupational safety management.

The most significant advantage of implementing a group of standards simultaneously within the framework of an integrated management system is the substantial savings in terms of financial, physical and human resources of the organization.

Despite the specificity of the energy industry, the IMS of most energy companies in Russia consists of the following common components:

- quality management system compliant with the international ISO 9001 standard (the equivalent of the Russian GOST R ISO 9001-2015 standard [2]);

- environmental management system compliant with the ISO 14001:2015 standard (the equivalent of the Russian GOST R ISO 14001-2015 standard [3]);

- occupational health and safety management system compliant with the OHSAS 18001 standard (the equivalent of the Russian GOST 12.0.230-2007 standard [4]);

- other management systems.

All of the management systems implemented within an organization require employee understanding of both the currently functioning systems and the systems being implemented. Although the procedures with regards to this matter are specifically formulated in the OHSAS 18001 and ISO 9001 standards, no such procedures exist for the environmental management system.

This is especially relevant during the implementation transition period associated with the implementation of the requirements of the new version of the ISO 14001:2015 standard.

Employees should have a full understanding of the importance of accomplishing environmental goals and tasks, for which they are responsible. In order to achieve the required level of employee understanding, an effective information support system should be created within the company. The organizational process associated with this training system should focus on changing employee attitudes towards environmental problems, fostering environmental consciousness and obtaining information about the possible ways and methods of reducing the negative impact on the environment.

The object of this research was the integrated management system of OOO LUKOIL-Permnefteprodukt, one of the largest interregional petroleum product suppliers among the LUKOIL group of companies.

In 2014, an audit (survey) was carried out in 12 branches of the company located in Yekaterinburg and Sverdlovsk Oblast (accounting for 15\% of the total 
number of company branches). The results of the research showed that the company staff did not possess a full understanding of the organization's environmental culture and policy or the main documents associated with ensuring environmental safety. Employees and experts throughout the organization had no understanding of the significance of their specialization and of their ability to introduce changes to the current functioning system. Employees were not familiar with the environmental aspects of their work.

The authors developed a solution in the form of an electronic educational resource to deal with this situation. The resource provided an opportunity for employees at all levels of the organization to gain an understanding of the current IMS. Particular emphasis was placed on the environmental management system (EMS).

\section{The rate of change in the number of issued ISO international standard certificates}

Due to the lack of integrated statistical data in the area of development and implementation of integrated management systems both in the Russian Federation and the world, it is not currently possible to accurately describe the situation with regards to this matter.

According to the literature on the subject, it is believed that more than $80 \%$ of IMSs are created and certified on the basis of the product quality management system (ISO 9001). The implementation of several international standards simultaneously within the IMS framework involves carrying out an evaluation of compliance with the criteria of various international standards. Therefore, compliance certificates are issued for each management system separately. The statistical data provided by the International Organization for Standardization reflects the total number of certificates issued in accordance with each specific international standard, not for the IMS as a whole.

The structure of the new version of the ISO 14001 standard has changed radically. This improvement was introduced in order to streamline the integrated application of management system standards within a single organization. It involves managing operations in accordance with a common procedure while taking into account the requirements in the areas of quality, ecology and occupational safety [5].

The rate of change in the number of issued ISO International Standard Compliance Certificates in the Russian Federation is illustrated in Table 1 and in the bar chart (Figure 1) below [6].

The largest energy companies in Russia have all implemented and certified the EMS. Explosive growth in EMS implementation took place until 2010. However, employees in these organizations seemed to lack motivation during the implementation of the EMS. The possession of the compliance certificate is not a guarantee of improvement in the quality of the environment [7]. The analysis of the government's environmental pollution monitoring data within the Russian 
Table 1: The rate of change in the number of issued ISO international standard certificates in the Russian Federation.

\begin{tabular}{|c|c|c|c|c|c|}
\hline Standard/year & 2010 & 2011 & 2012 & 2013 & 2014 \\
\hline ISO 9001 & 62265 & 13308 & 12488 & 11764 & 11301 \\
\hline ISO 14001 & 1953 & 1093 & 1090 & 1272 & 1263 \\
\hline ISO 50001 & - & 1 & 8 & 25 & 81 \\
\hline ISO 27001 & 72 & 31 & 27 & 48 & 50 \\
\hline ISO 22000 & 191 & 143 & 171 & 279 & 482 \\
\hline
\end{tabular}

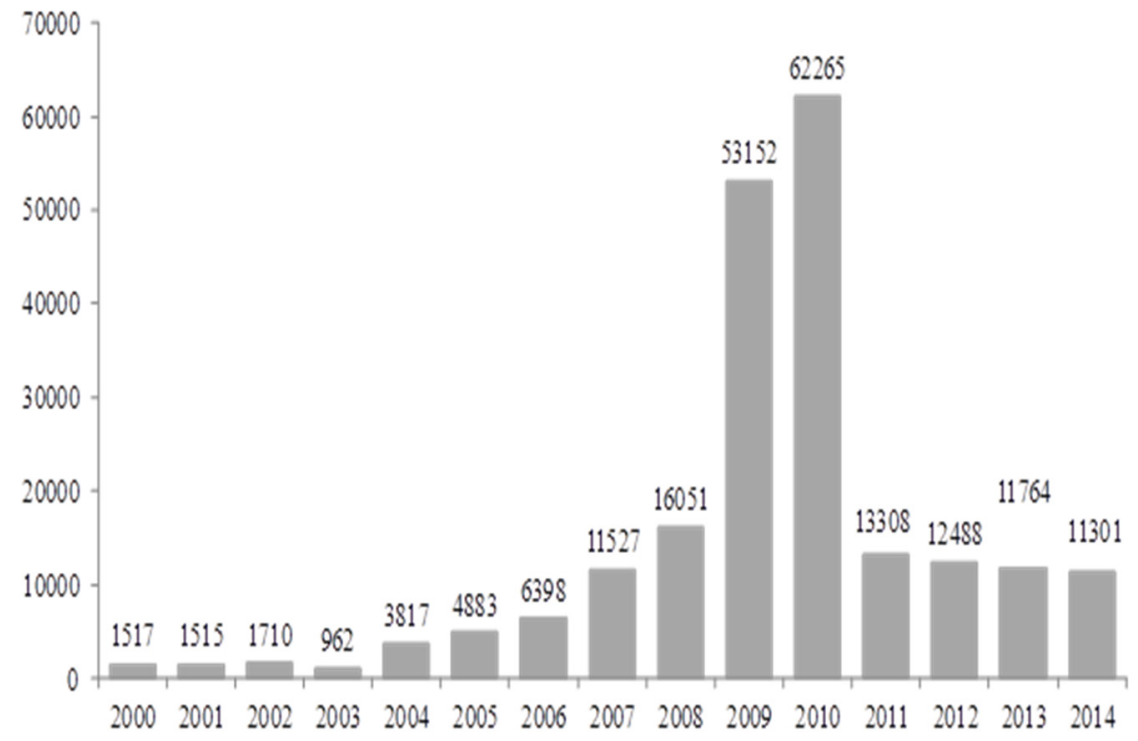

Figure 1: Change in the number of issued ISO 9001 certificates in the Russian Federation.

Federation shows that there has been no significant decrease in the level of environmental pollution during the recent years, according to both the individual indicators and the integrated assessment [8].

The comparison of the number of ISO 14001 certificates per 100000 people in the country's population with the Environmental Performance Index does not show a significant level of statistical correlation either [9].

Data analysis shows that the situation in Russia corresponds to global trends on the whole. On the one hand, there is an evident decline in the implementation of the ISO 9001 and ISO 14001 standards. On the other hand, there is steady growth in the implementation of the ISO 50001, ISO 27001 and ISO 22000 standards.

The total number of certificates issued in the world in 2014 (1609294) reflects moderate growth for practically all ISO standard systems compared to the previous year (Tables 2 and 3). 
Table 2: Total number of issued ISO international standard compliance certificates, $\%$ change by year.

\begin{tabular}{|c|c|c|c|c|c|}
\hline Standards & 2010 & 2011 & 2012 & 2013 & 2014 \\
\hline ISO 9001 & 1118510 & 1111698 & 1096987 & 1129446 & 1138155 \\
\hline$\%$ & - & -1 & -1 & 3 & 1 \\
\hline ISO 14001 & 251548 & 267457 & 284564 & 301647 & 324148 \\
\hline$\%$ & - & 6 & 6 & 6 & 7 \\
\hline ISO 50001 & 0 & 461 & 2236 & 4826 & 6778 \\
\hline$\%$ & - & - & 385 & 116 & 40 \\
\hline ISO 27001 & 15626 & 17509 & 19620 & 22293 & 23972 \\
\hline$\%$ & - & 12 & 12 & 14 & 7 \\
\hline ISO 22000 & 18580 & 19980 & 23278 & 26847 & 30500 \\
\hline$\%$ & - & 8 & 17 & 15 & 14 \\
\hline ISO 13485 & 18834 & 20034 & 22317 & 25666 & 27791 \\
\hline$\%$ & - & 6 & 11 & 15 & 8 \\
\hline ISO 16949 & 43946 & 47512 & 50071 & 53723 & 57950 \\
\hline$\%$ & - & 8 & 5 & 7 & 8 \\
\hline Bсего & 1467044 & 1484741 & 1499073 & 1564448 & 1609294 \\
\hline
\end{tabular}

Table 3: Countries with the most ISO international standard certified companies in 2014.

\begin{tabular}{|l|c|c|c|c|c|c|c|c|}
\hline \multirow{3}{*}{ Country } & \multicolumn{7}{|c|}{ International standards / } \\
\cline { 2 - 10 } & $\begin{array}{c}\text { ISO } \\
9001\end{array}$ & $\begin{array}{c}\text { ISO } \\
14001\end{array}$ & $\begin{array}{c}\text { ISO } \\
50001\end{array}$ & $\begin{array}{c}\text { ISO } \\
27001\end{array}$ & $\begin{array}{c}\text { ISO } \\
22000\end{array}$ & $\begin{array}{c}\text { ISO } \\
13485\end{array}$ & $\begin{array}{c}\text { ISO } \\
16949\end{array}$ & $\begin{array}{c}\text { ISO } \\
22301\end{array}$ \\
\hline China & 342800 & 117758 & 65 & 2002 & 10212 & 2559 & 22801 & - \\
\hline Italy & 168960 & 27178 & 294 & 970 & 1214 & 2695 & 1240 & 12 \\
\hline Japan & 45785 & 23753 & 59 & 7181 & 1043 & 1076 & 1411 & 200 \\
\hline Spain & 36005 & 13869 & 310 & 701 & 537 & 331 & 934 & 28 \\
\hline Germany & 55363 & 7708 & 3402 & 640 & 403 & 2890 & 3356 & 7 \\
\hline $\begin{array}{l}\text { United } \\
\text { Kingdom }\end{array}$ & 40200 & 16685 & 376 & 2261 & 104 & 1890 & 595 & 345 \\
\hline Russia & 11301 & 1263 & 81 & 50 & 482 & 104 & 294 & 1 \\
\hline USA & 33008 & 6586 & 58 & 664 & 284 & 5175 & 4112 & 40 \\
\hline France & 29122 & 8306 & 270 & 161 & 632 & 1059 & 1006 & 7 \\
\hline
\end{tabular}

The ISO 9001 standard (quality management) and the ISO 14001 standard (environmental management), which are regarded as the basis for the IMS, have shown a $1 \%$ and $7 \%$ growth respectively. China currently takes on the most active role in the implementation of these standards. China is followed by Japan and the European countries. Russia holds one of the last places with regards to the implementation of the ISO 9001 and ISO 140001 standards.

Market stabilization is compensated for by an interest in three specific systems, which demonstrate the most sustainable growth.

The ISO 50001 standard (energy management system) demonstrates a growth of $40 \%$. The list of countries implementing this standard is headed by Germany, 
which accounts for half of the 6778 issued certificates. The implementation of the ISO 22000 standard (food safety management system) remains in steady demand with a growth of $14 \%$.

The implementation of the ISO 16949 standard demonstrates a steady growth of $8 \%$ in the automotive sector. This points to possible economic growth trends within the automotive industry.

The new ISO 22301 standard (Societal security. Business continuity management systems. Requirements) was adopted in 2012 and showed a growth of 1700 certificates. This proves that it is necessary for organizations to protect themselves from collapse in times of crisis. The leaders with regards to the implementation of this standard are India (480), Great Britain (345) and Japan (200) [6].

\section{The development of the electronic educational resource}

The key factor determining the effectiveness of the integrated management system is full employee and business unit participation. The IMS policy should be brought to the attention of each employee. However, in most cases, if the policy comes in the form of a text document, it is difficult to comprehend and requires thorough employee learning. In order to gain a full understanding of these policies, employees need to possess a specific set of specialized knowledge and skills.

This is especially relevant when introducing the EMS in the workplace because, as mentioned earlier, mandatory labor protection and industrial safety training is carried out in all organizations. In this case, the organization's environmental policy should also be brought to the attention of all company personnel. It is a known fact that the number of employees in each company varies over time. New employees may need some time to grasp the policy details [7].

OOO LUKOIL-Permnefteprodukt made the decision to develop an electronic educational resource (EER) and to create a publication platform within the scope of the research project. The resource was made accessible to all company employees. It was assumed that this measure would improve the educational aspect, employee awareness and employee competence with regards to the IMS $[11,12]$.

Employee training may be executed using differentiated programs according to the level of employee involvement in the IMS. It is worth pointing out several learning units, including programs for the organization's top managers, internal audit (inspection) experts (auditors), the technical staff and other employees.

Significant financial investment is required for outsourcing third-party consultants, educational seminars and training. Due to the large number of employees in the organization, this may not be a viable option. The creation of an EER may be seen as a more rational and cost-effective way of solving the specified problems and improving the IMS of OOO LUKOIL-Permnefteprodukt.

The electronic educational resource is an automated training system, which accumulates and grants access to methodical and information and reference materials regarding the functioning of the IMS of OOO LUKOILPermnefteprodukt. The EER is a collection of pages containing interconnected 
Internet links, which are associated with a specific topic. It is presented in the form of a website. The EER possesses a hypertextual structure, which enables learners to determine the optimal learning approach and a comfortable working pace.

The electronic educational resource contains 5 structural elements:

1) The section "Home" reflects the information about the resource, target audience, the objectives of the course and the intended result.

2) The section "Public Corporation LUKOIL Policy" is the main document in the integrated management system, it includes the intentions and principles of the enterprise on the industrial safety, labor and environment protection. The section presents excerpts from the Policy; one may also read the full text of the document using a hyperlink.

3) The section "Industrial Safety, Labor and Environment Protection Management System" describes the activities within the limits of the ISMS, L\&E P.

The "Industrial Safety" subsection contains the definitions of terms such as "industrial safety" and "accident", information about the types of business activities associated with industrial safety and the company's obligations with regards to operating dangerous production facilities.

The "Labor Protection" subsection contains the definition of the term "labor protection", information about the components of the labor protection system, employer obligations with regards to providing a safe environment and labor protection and labor protection staff obligations.

The "Environmental Protection" subsection contains the definition of "environmental protection", information about the organization's strategic goals within the scope of environmental protection, the environmental policy and significant environmental aspects.

4) The "Learning" section contains 2 training courses in the areas of ISMS, LP and EP. These courses correspond to different levels of employee preparation and are aimed at 2 categories of employees: the company's management and experts and all other employees of the organization.

The training courses differ in the objectives, content, scope, and evaluation criteria.

The description of the training course aimed at the company's management and experts.

The objectives of the course:

a) to obtain the knowledge and skills necessary to form the organization's policy in the areas of information security (IS), labor protection (LP) and environmental protection (EP);

b) to learn about the legal requirements in the specified fields.

Type of training: an overview course on the strategic significance of the organization's management system.

Course duration: 5 hours.

Assessment method: a test comprising of 20 questions.

The description of the training course aimed at all of the organization's employees. 
The objectives of the course:

a) to learn about the organization's policy and objectives and tasks in the areas of industrial safety, labor protection and environmental protection;

b) to provide a framework for safe methods of conducting work.

Type of training: an introduction course on information security (IS), labor protection (LP), environmental protection (EP) and on the basics of the organizational management system.

Course duration: 3 hours.

Assessment method: a test comprising of 20 questions.

When taking the final test, employees specify their name, surname and position in the company. The software database forms a list of 20 questions, which the employees have 40 minutes to answer. All questions are numbered and have a corresponding description depending on the question type (one correct answer, several correct answers, specifying compliance, etc.). If employees have any difficulties in answering a specific question, they may skip to the next question. All unanswered questions are displayed in the "List" menu.

After an employee is finished taking the test, the following statistical information is displayed:

- the score obtained for answering correctly;

- the score required to pass;

- the time taken;

- the results of the test.

A report containing the test results is formed and sent via email to both the employee and the coordinator. The coordinator is responsible for ensuring that all assigned employees pass the course.

5) The "Help" section contains troubleshooting information for employees regarding the functioning of the website and the course. The section also contains the coordinator's contact information and a feedback form for employees.

The electronic educational resource is available online to all users of the Internet. This is one of the requirements of the international standards associated with employee information support.

\section{The results of the study}

In order to optimize the learning process of OOO LUKOIL-Permnefteprodukt employees, the authors propose a combination of two forms of training: a) fulltime training, which involves detaching employees from the production process and $b$ ) remote training, which involves electronic learning without the need to detach the employees from the production process.

The organization's top management and experts responsible for the creation, maintenance and improvement of the management system undertake at least 72 hours of training and professional development classes in certified consulting centers. Increased knowledge assessment requirements are applied to this group of employees. All other employees (including experts, which are not specialized with regards to the IMS, and blue-collar workers) undertake training via the 
electronic educational resource throughout the first month of work starting from the day they assume their position in the organization.

Extramural seminars, involved with detaching the employees from the production process, should be attended by the organization's top managers and middle managers responsible for the functioning of the IMS. All other employees should take the electronic training course. The integration of these two training methods will enable the organization to both increase the effectiveness and efficiency of the management system and cut the costs of employee training.

The specified course will enable the employees to grasp the following aspects:

a) the significance of compliance with the company policy regarding IS, LP and EP and with the procedures and requirements of the integrated management system;

b) significant environmental aspects, dangers and professional risks and the actual and potential impact on the environment and human health;

c) the benefits of improving the effectiveness of each employee for the environment and human health;

d) employee obligations and responsibility in achieving compliance with the requirements of the integrated management system;

e) the potential consequences of deviating from the established procedures.

\section{Conclusions}

As a result of creating an integrated management system, industrial organizations must continuously revise all of the system's components and ensure the necessary level of employee competence in the areas of industrial safety and environmental management, all the while managing their current production processes.

The software product is developed for the purpose of familiarizing employees with the organization's IMS. This product will enable the company staff to obtain a clear understanding of the functioning of the management system and establish awareness of the management system requirements applicable to organizations with an emphasis on the EMS. Training employees on the basis of EER will enable the organization to achieve the following results: the reduction of the training duration;

- a reduction in training time;

- a reduction in training costs;

- a clearer and more precise execution of work;

- a reduction in the amount of compensation payments;

- improved employee effectiveness.

By carrying out regular assessments of employee knowledge with regards to this subject, the company will be able to increase the overall effectiveness of the organization's management and control systems. 


\section{References}

[1] Berezyuk, M. \& Rumyantseva, A., A concept of transition to the best available technology as a basis for sustainable development of power industry. International Journal of Sustainable Development and Planning, WIT Press, V. 10. pp. 635-649, 2015.

[2] National standard of the Russian federation, [in Russian], Quality management systems. Requirements. http://docs.cntd.ru/document/ $\underline{1200124394}$

[3] National standard of the Russian federation, [in Russian], Environmental management systems. Requirements with guidance for use. http://www.pqm-online.com/assets/files/pubs/translations/std/iso-140012015-(rus).pdf

[4] National standard of the Russian federation, [in Russian], Occupational safety standards system. Occupational safety and health management systems. General requirements. http://docs.cntd.ru/document/gost-12-0230-2007-ssbt

[5] Khoroshavin, A., New Version of the Standard ISO 14001, [in Russian], Ecology of production, No 3. pp. 40-43, 2015.

[6] The ISO Survey http://www.iso.org/iso/iso_survey executivesummary.pdf?v2014

[7] Itkin, B., Environmental Management Systems Certification and the Environmental Quality, [in Russian], Ecology of production, No 6. pp. 3241, 2015.

[8] State report "On the State and Environmental Protection of the Russian Federation in 2014". http://www.mnr.gov.ru/regulatory/list.php?part=1756

[9] 014 EPI Results. Yale University, 2015. http://epi.yale.edu/epi/countryrankings

[10] Itkin, B., On the New Version of the Standard ISO 14001, [in Russian], Ecology of production, No 3. pp. 46-53, 2016.

[11] Zhomayko, O.\& Berezyuk, M., The Process of the Enterprise Personnel Training under the Integrated Management System, [in Russian], The Western Siberia Academic Journal, No 2 (57), V. 11, p. 89, 2015.

[12] Zhomayko, O.S., The Enterprise Personnel Training Optimization Within the Integrated Management System Improvement. Proc. of the 9th Int. Conf. Environmental Safety Management System, eds O.S. Zhomayko, M.V. Berezyuk: Yekaterinburg, pp. 196-200, 2015. 